\title{
Is your IT investment adding value to the Enterprise?
}

\author{
Siva Sankaran \\ ICT Manager, \\ EMAL, P O Box 111023, \\ Abu Dhabi, U A E \\ adviser4it@aim.com
}

\begin{abstract}
Choosing right IT initiatives to enhance the performance of an Enterprise is critical. Business are required make tough decisions on where to invest their cash while more and more projects compete for the organization's tight resources. IT executives must present compelling and credible business cases to win corporate approval to secure funds for their projects. A framework for measuring the value realizable out of an IT investment initiative is presented in this paper.
\end{abstract}

Business case. IT projects. Project Approval. Investment decisions. Business Value.

\section{INTRODUCTION}

An Organization's IT investment decisions demand proven economic justification. This report details a framework for measuring the value realizable out of an IT investment initiative, enabling a shift in IT decision making process to be a customer-focused, value driven process. By having a systematic approach to measuring IT's success in terms of Dollar value contributions, we are trying to shift the perception of IT as cost center to IT as a value center and also to aid in allocation of resources to most essential areas.

Though this scrutiny adds extra work to IT professionals, it also strengthens the benefits our business receives. Measuring this value has never been an easy task. The document defines what is meant by business value. IT provides some products \& services which may not need business value metrics assessment (e.g. assessing the value of using a telephone versus mailing a letter etc...) And this document is not applicable to those initiatives. And finally the framework establishes a tool to jumpstart the measurement and valuation process.

\section{BUSINESS CASE}

A comprehensive business case preparation is key to the successful implementation and long term value of the IT portfolio of investments. To be effective business cases must:

- Verify alignment to strategic objectives of an organization.
- Present the financial impact of scalability. Must be flexible to accommodate future business environment driven changes.

- Incorporate risks associated with the project success and assess the risk of benefits not being realized

- View the economics in business terms first and not be technology centric.

- Place the initiative within a portfolio context: Possible consolidation and redundancy areas would emerge from this.

- Exploit synergies: investment decisions should be compatible with the roadmaps and offer shared capabilities for multiple areas.

A comprehensive business case displays the value of capital initiatives by measuring costs (TCO), benefits, risks \& scalability. The business case should identify accountabilities supported by clear and relevant business metrics \& be a living operational management tool updated though the full life cycle of the project.

\subsection{What is Business Value?}

Estimating business value from these investments requires more than an $\mathrm{ROI}$ section in a business case. The objective of investments is to have a positive impact on business outcomes like revenue, operating expense, asset efficiency, and market share or customer satisfaction. Benefits can be 
tangible or intangible, directly measurable or indirectly measurable, immediate or deferred.

To successfully measure the value of IT, we establish a common language that everyone in the
Organization could understand. Using the definition of Business Value and the concept of "Value Dials" explained below, we go on to present a tool that helps in IT value estimation.

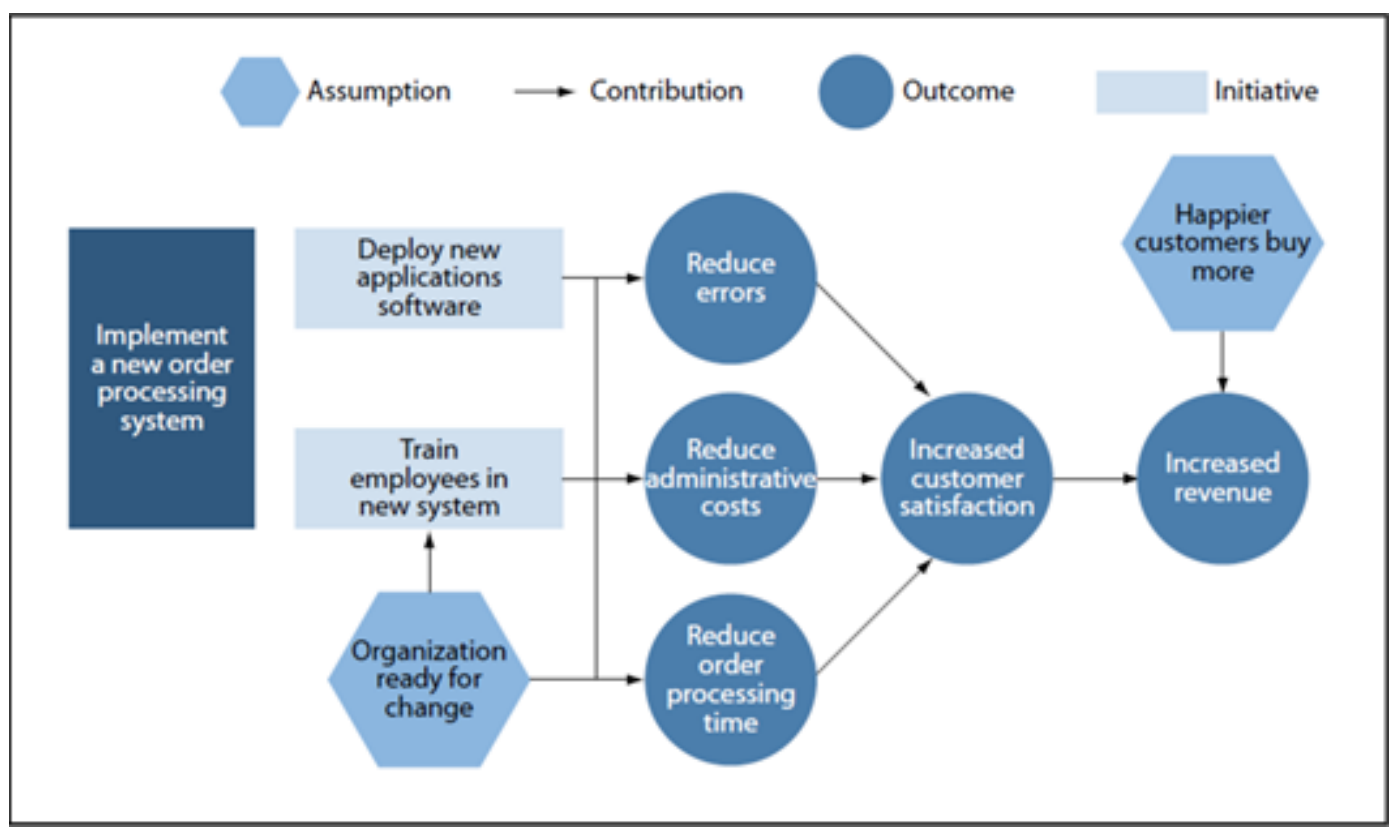

Figure 1: Sample Results Chain for an Order Processing System

Business Value is defined as the benefit represented in dollar terms for an Organization's business areas that is a result of information technology solutions or services deployed as evidenced by the following:

- $\quad$ Financially derived from customer (internal \& external) cost savings or benefits.

- Technology investments that advance the industry there by optimizing on operational expenses.

- Deliverables and results that support solving customer (internal \& external) needs or challenges

- Direct contribution to the Organization's market position or revenue

\subsubsection{Standard metrics "Value Dials":}

A concept of "Value Dials" is proposed to describe specific, observable, quantifiable elements of business goals.

"Value Dials" form a framework of measurement activities that help the IT team to establish \& articulate the value of IT projects in a standard, repeatable manner.

The major challenge in implementing a benefits realization process is "how to model the flow from project activities through to the value?" The "results chain technique" developed by John Thorp [1] is useful as a concept. Estimation of Business Value from IT projects has been analyzed in literature [2], [3]. Figure 1 shows a sample Results Chain for an Order Processing System.

Based on the references cited above, the paper establishes following lists:

(i) All possible IT of initiatives that can be undertaken in any enterprise typically is shown Table 1 and Table 2.

(ii) Table 3 shows a master list of "Value Dials" showing the possible benefits that each one of the above initiatives could bring in and also a calculation example for quantifying the value in financial terms.

\subsubsection{Measurement Tool \& BVI:}

Business Value Index (BVI) is a composite index of factors that impacts the value of an IT investment and is evaluated on two vectors:

(i) IT Business Value (impact to the Organization's business) is estimated using the "Value Dials" concept described above and presented as a measurement spreadsheet showing the financial benefit of the investment by estimating IRR, or Payback period.

(ii) Impact to "IT efficiency" [uses factors such as IT agility, potential to reduce IT costs 
and alignment to IT strategy by concentrating on too many projects that could put strain on IT department].

A template for presenting of how the "Business Value" and "IT efficiency" could be impacted due to implementing an initiative is presented in Figure 2 as a Business Value Diagram.

BVI which is a composite index of (i) \& (ii), is presented as a preferred metric due to its simplicity and it goes beyond using purely financial criteria (being a quantitative evaluation) by combining the qualitative perception of benefits. Figure 3 shows a sample Business Value Index diagram presented as a bubble chart. The size of the bubble shows the quantitative benefit and the quadrant of the bubble shows qualitative perceptions of the benefits for any initiative.

A workable spreadsheet* tool is developed capture the data and calculate the Business Value for any initiative which needs a business case support for Investment. Table 5 shows the Format of this tool with sample data. The all in one worksheet captures the ROI \& Business Value bubble, based data entered in the cost $\&$ benefits summary cells. The initiator should also select the quadrant in BVI Chart applicable to the initiative. The summary ROI \& Business Value Index format will the one used to evaluate investment proposals and also to aid in realization efforts.

\section{PRACTICAL EXAMPLES}

These techniques were applied to two project initiatives and shown here below as illustration cases.

\subsection{Case 1}

For a CCTV camera \& Attendance reporting application and the project, sponsors learned that:

- The initiative falls under the types "Security", "Office Productivity \& Compliance" domains.

- And benefit realization would be through "Head Count Reduction", "Head Count Productivity" \& "Risk Avoidance" Value Dials.

- Further quantifying these benefits, the team found that the project has a payback period of 3 years with $39 \%$ as IRR (Internal Rate of Return) resulting in a favorable BVI (Business Value Index) of Improved Business Value with no or limited IT efficiency penalty. The calculation details for the above examples are presented in Table 4 to explain the approach.

\subsection{Case 2}

For a Backup Data center project, to build a DR facility, the project sponsors learned that:

- The initiative falls under the types "Improved performance, reliability, security, manageability, productivity", "Information security" and "Business Continuity" domains.

- The benefit realization would be through "improved system availability with very low downtimes" which aids in lower inventory buildup, better planning, avoiding delays in accounts receivables, "business competitiveness and reliability as a partner" Value Dials.

- Further quantifying these benefits, the team found that the project has a payback period of 1 year with $300 \%$ as IRR (Internal Rate of Return) resulting in a favorable BVI (Business Value Index) of Improved Business Value and increased IT efficiency.

\subsection{Case 3}

In contrast, for a mobility project study undertaken by the team, it was found that the payback period was more than 9 years and a very low IRR of $2 \%$. This is mainly because the organization's business workflow processes were not geared to leverage mobile applications.

\section{CONCLUSIONS}

The presentation thus summarizes a workable methodology and presents a Decision Support Tool for IT investments. It also helps in selection and evaluation of multiple projects competing for the same resources.

\section{REFERENCES}

Book: John Thorp (2007) The information Paradox, Fujitsu consulting.

Book: David Sward (2006) Measuring the Business Value of Information Technology, Intel Press.

Technical documents: Craig Symons and Sharyn Leaver (2009) Programs not Projects bring Business Value, Forrester Publications, April, 2009 


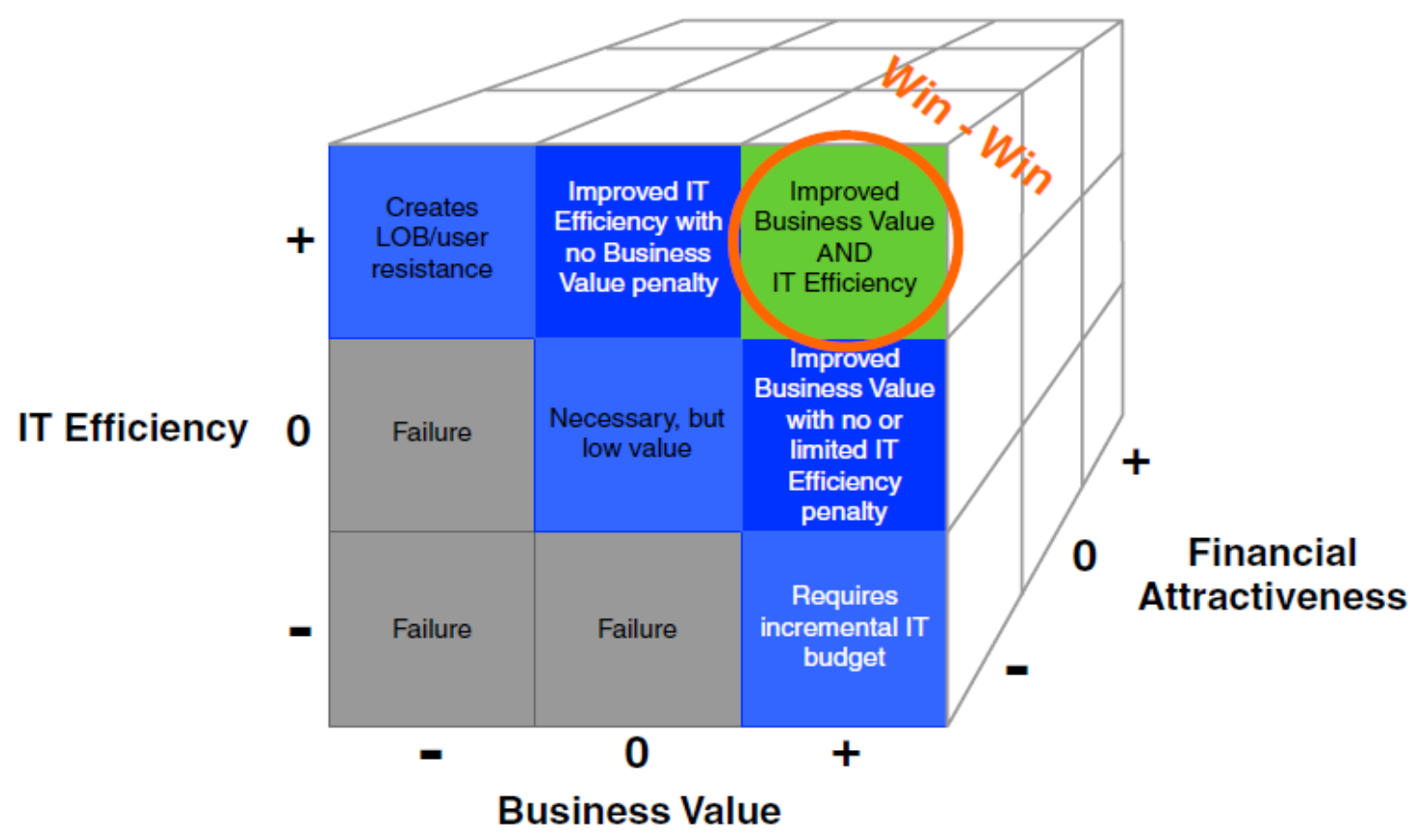

Figure 2: Business Value Diagram

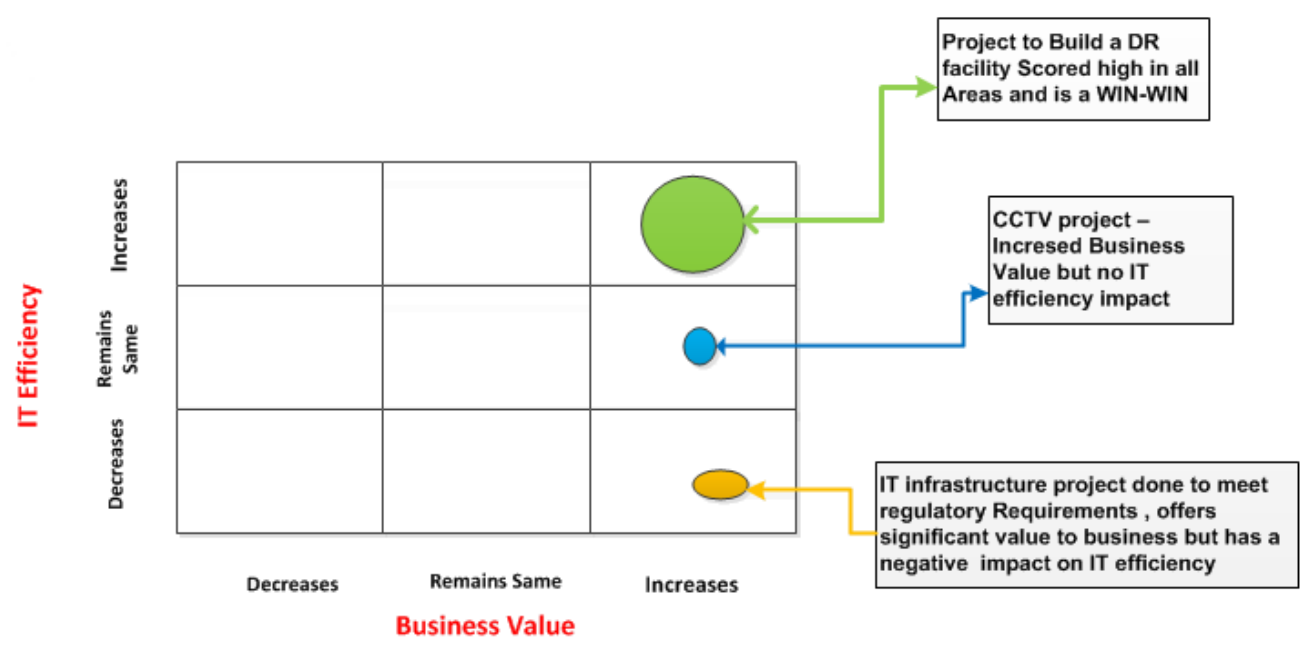

Figure 3: Sample Business Value Index diagram 
Table 1 : List of Initiatives: Infrastructure/Platform technology

\section{Initiative Type}

PC HW/OS Upgrades

Server HW/SW Upgrades

Infrastructure Mgmt. / Networking

Storage

Security

Application Development / Architecture

Compliance, Governance, Risk

\section{Outsourcing}

Wireless/ Mobility / telecom

\section{Key benefits}

- Improved performance, reliability, security, manageability, productivity

- Notebook, desktop, thin-client

- Virtualization, consolidation, clustering

Improved performance, reliability, manageability, security

- Multi-core, 64-bit, RISC/Itanium, x86

- Web servers, application servers, DBMS servers, data warehouse servers, infrastructure servers, high performance computing servers

- Asset inventory/management, OS management, configuration management, change management, systems management, software distribution, application packaging

- Directory services, group policy objects

- provisions due to movement of offices

- IPV6, LAN, WAN

- Digital storage of business data and documents

- Archival, records management, tape backup, SAN, NAS, disk arrays, iSCSI, fiber channel

- Capacity management, performance analysis, storage provisioning, quota management, event management

- Security planning, assessment, incident/breach management

- Identity and access management, encryption, smartcards, authentication, authorization, patch management

Firewalls, antivirus, anti-malware, anti-spyware, network access control, information and data rights management

- Improved software quality, integration, usability

- Custom developed software

Middleware, application server

- Web services, Service-Oriented Architecture, SaaS (software as a service)

- Enterprise architecture (EA)

- Methods and software to ease compliance with regulations such as HIPPA, Sarbanes-

Oxley, Basel II

- ITIL, COBIT, Six Sigma, CMM, ISO 17799/9000, PMBOK

- Maturity models (Microsoft's Infrastructure Optimization Maturity Model)

Portfolio management, IT-business alignment, balanced scorecard, service level

management, risk management · Business continuity-disaster planning / recovery

- IT governance, policies, internal audit, monitoring

- Outsource IT and business processes, applications, infrastructure, or initiatives to reduce costs and improve results

- Infrastructure management: helpdesk, on-site support, desktop management, data center services

- BPO - business process outsourcing

- Offshore services

Application outsourcing, web hosting

- Wireless e-mail, mobile access to line-of-business applications, unified communications

VPN, mobile remote access, telecommuting

- Handheld devices, smartphone, PDAs

Wireless LANMAN, 802.11n, WiMAX, CDMA, UMTS, GPRS, EDGE.

$P A B X$, Call Manager, Leased Circuits, Radio communications

- VOIP Voice over internet protocol 
Table 2: List of Initiatives: Business Technology Initiatives

\section{Initiative Type \\ Office Productivity Software

Messaging/
Collaboration
Content
Management
E-commerce /
Internet

Business Process Mgmt. / Integration

Business Intelligence / Data Mgmt.

Business Applications (Vertical, LOB)

CRM

\section{Key Features, Capabilities, Benefits}

- Word processing, spreadsheets, personal databases, presentation graphics software, personal information management, note-taking, task and project management, document creation and publishing

- E-mail, calendaring/scheduling, task management, unified communications.

Real-time collaboration, presence, instant messaging, web conferencing

- Social computing, blogs, wikis

- Team workspaces, project management, discussion threads, document workflow

- Document management, web content management, document imaging, records management, digital asset management

- Knowledge management, information management. Intranets, Extranets, Portals

- Web sites for external business information dissemination, marketing, sales transactions, etc.

- Web storefronts, shopping cart management, taxation, personalization, transaction management, settlement and product visualization

- B2B, B2C, AJAX, mashups

- Process modeling, monitoring and management .

Workflow, business rules, automation, electronic forms

- $B A M$ (business activity monitoring).

EAI (enterprise application integration)

- Database management systems (DBMS), data warehousing, data marts, online transaction processing (OLTP)

- Master data management, data quality, metadata

- Financial planning, corporate performance management, reporting, analytics, dashboards, scorecards, enterprise search, ETL, OLAP, query

- Wide variety of specialized software that helps organizations streamline business processes and improve results

Customer Relationship Management.

. Sales force automation, marketing campaign management, customer information management, order entry, customer service management, customer analytics, product configurators

- Hosted CRM

- Enterprise resource planning: supply chain management, operations/production management, inventory management, planning/scheduling,, finance/accounting, human resource management, product management, warehouse management, logistics, purchasing, order entry, CAD, etc. 
Table 3: Value Dials List

SI. No Value Dials

1 Days of Inventory ${ }^{1}$

2 Days of Receivables

3 Headcount Reduction

4 Headcount Productivity

5 Headcount Turnover

6 System End-of-Life

7 Materials Discounts

8 Capital Hardware, and Software Avoidance

9 Unit \& Other Cost Avoidance

10 Factory Uptime

11 Scrap Reduction

12 Risk Avoidance

13 Time-to-Market

14 Open New Markets

15 Optimize Existing Markets

16 Cross-Selling

17 Vendor of Choice

${ }^{1}$ Calculation against each Value Dial gives the value of the benefit in Financial terms.

For e.g.: benefits under Value Dial " 1 " can be calculated as equal to (Value of 1 day inventory) $x$ (days of inventory stocking reduced) $\times 15 \%$ (weighted average cost of capital) 
Table 4: Sample Value Dial calculations

\begin{tabular}{|c|c|c|c|c|c|c|}
\hline $\begin{array}{l}\text { Value } \\
\text { Dial } \\
\text { row }\end{array}$ & $\begin{array}{l}\text { VALUE } \\
\text { DIAL }\end{array}$ & VALUE DIAL DEFINITIONS & $\begin{array}{l}\text { VALUE DIAL } \\
\text { CALCULATIONS }\end{array}$ & Unit contribution & units & $\begin{array}{l}\text { total per year saving } \\
\text { or expense avoidance } \\
\text { (1 USD=3.68 AED) }\end{array}$ \\
\hline
\end{tabular}

Only items 3 \& 4 of the value dials described in table 3 are quantifiable for the initiative cited under case 1 - refer details below

\begin{tabular}{|c|c|c|c|c|c|c|}
\hline 3 & $\begin{array}{l}\text { Headcount } \\
\text { Reduction }\end{array}$ & $\begin{array}{l}\text { Solutions that enable reduction in } \\
\text { human resources or absorb business } \\
\text { growth without growing headcount. } \\
\text { HR can either move employees to } \\
\text { areas of greater return or put teams } \\
\text { on new projects. Reduction in } \\
\text { manpower can be due to automation } \\
\text { or error elimination (avoiding costly } \\
\text { reworks), or due to productivity gains } \\
\text { etc... These are priority areas for the } \\
\text { company. }\end{array}$ & $\begin{array}{l}\text { (Number of } \\
\text { headcount reduced or } \\
\text { avoided) } x \text { (average } \\
\text { employee cost rate for } \\
\text { job type) }\end{array}$ & $\begin{array}{l}\text { as CCTV ensures efficient } \\
\text { monitoring from a central } \\
\text { place, } 1 \text { FTE can be saved }\end{array}$ & $\begin{array}{l}\text { salary of } 1 \text { FTE } 96000 \\
\text { AED/year (assumed) }\end{array}$ & $96 K A E D$ \\
\hline 4 & $\begin{array}{l}\text { Headcount } \\
\text { Productivity }\end{array}$ & $\begin{array}{l}\text { Gains In headcount efficiencies or } \\
\text { effectiveness, but actual people are } \\
\text { not avoided or reduced. Headcount is } \\
\text { expected to produce more through } \\
\text { these gains due to the additional time } \\
\text { efficiencies. }\end{array}$ & $\begin{array}{l}\text { (Number of } \\
\text { employees affected) } x \\
\text { (time) } x \text { (average } \\
\text { (employee costs) } x \\
(50 \%)\end{array}$ & $\begin{array}{l}\text { T\&A system eliminates } \\
\text { late coming \& } \\
\text { unauthorized absences } \\
\text { leading to higher } \\
\text { productivity. }\end{array}$ & $\begin{array}{l}\text { Assume each day some } \\
100 \text { employees work } 30 \\
\text { minutes more due to } \\
\text { system discipline. This } \\
\text { results in saving of } \\
100 X 35 \text { AED(av. hourly } \\
\text { rate) * } 365 \text { days }=1.25 \\
\text { Million AED per year }\end{array}$ & 1.25 M AED \\
\hline \multicolumn{7}{|c|}{ Only items 12 of the value dials list described in table 3 are quantifiable for the initiative cited under case 2 - refer details below } \\
\hline \multirow[t]{2}{*}{12} & \multirow[t]{2}{*}{$\begin{array}{l}\text { Risk } \\
\text { Avoidance }\end{array}$} & \multirow{2}{*}{$\begin{array}{l}\text { Plant and facility protection systems } \\
\text { that prevent sabotage, vandalism, } \\
\text { theft of company's assets by } \\
\text { improving physical access security }\end{array}$} & \multirow[t]{2}{*}{$\begin{array}{l}\text { (Value of risk) } x \\
\text { (probability of } \\
\text { occurrence) }\end{array}$} & \multirow{2}{*}{$\begin{array}{l}\text { total value of assets in } \\
\text { Company location is } \\
\text { calculated as } 2 \text { MUSD } \\
\text { (movable) }\end{array}$} & $\begin{array}{l}\text { eliminate theft of say some } \\
\text { IT assets } 5 \text { laptops / year } \\
\text { saves 22,000 AED }\end{array}$ & $22 K A E D$ \\
\hline & & & & & $\begin{array}{l}\text { One sabotage or any other } \\
\text { natural calamity incident } \\
\text { in } 5 \text { years leading to half } \\
\text { day of production } \\
\text { stoppage resulting in loss } \\
\text { of revenue :: } 7.8 \text { Million } \\
\text { AED / } 5 \text { years which is } \\
\text { equal to } 1.57 \mathrm{M} \text { AED/year }\end{array}$ & $1.57 \mathrm{MAED}$ \\
\hline
\end{tabular}


Table 5. Results showing the ROI \& Business Value Index for Case 2: Back up Data Centre project.

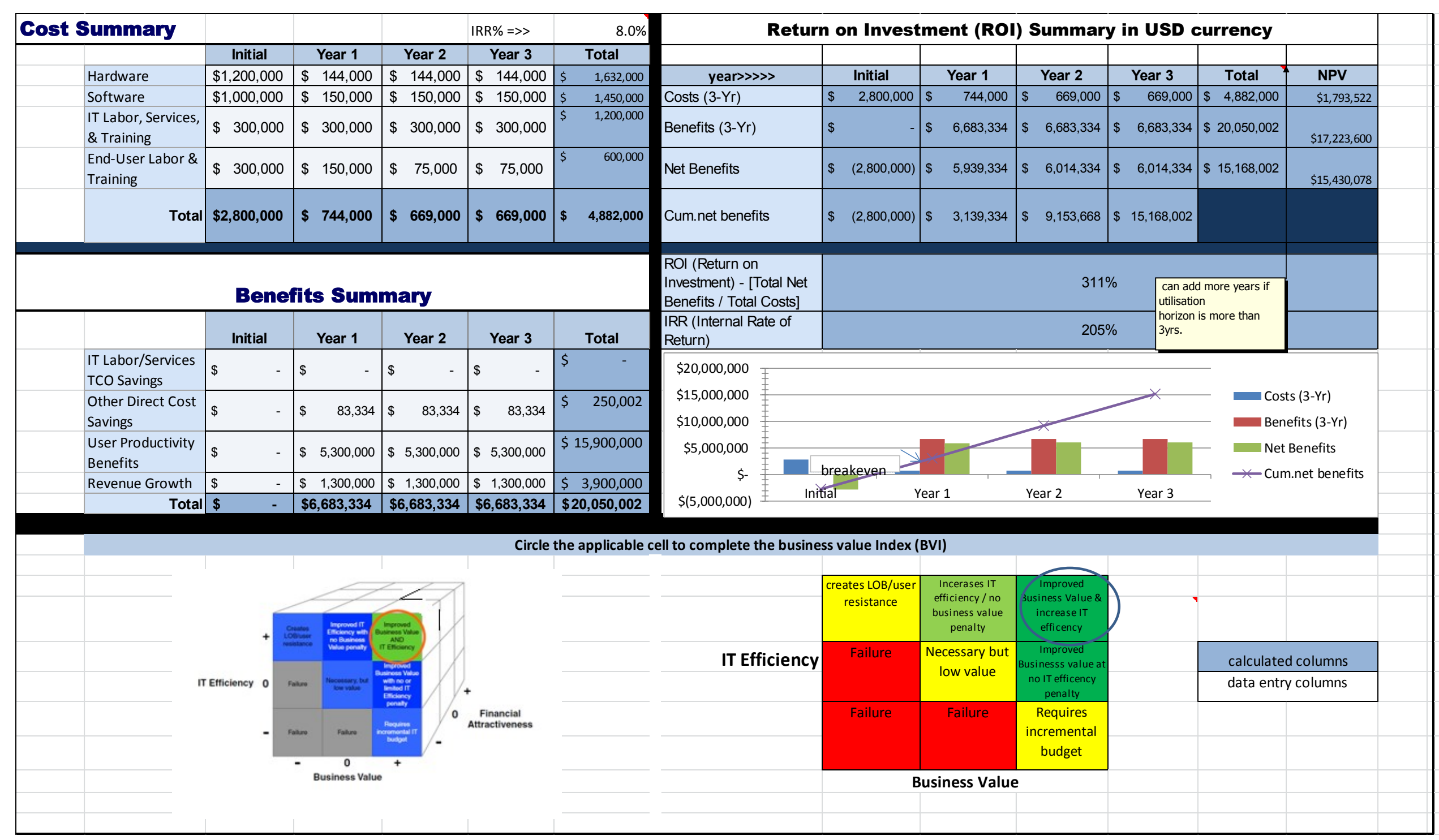

